\title{
Influence Of Organisational Culture On Strategy Execution In A South African Organisation
}

Melissa Reddy, Gordon Institute of Business Science, University of Pretoria, South Africa

Caren Scheepers, Gordon Institute of Business Science, University of Pretoria, South Africa

\begin{abstract}
Purpose: This study examines the effects of nine dimensions of organisational culture (uncertainty avoidance; gender egalitarianism; assertiveness; institutional collectivism; in-group collectivism; humane, future and achievement orientation; and power distance) on the dimensions of strategy execution (information sharing, leadership, rewards, performance, structure, employee commitment and coordination) within a fast-moving consumer goods (FMCG) company.

Design: A survey questionnaire covering demographics, organisational culture and strategy execution was distributed electronically. Following assessment of reliability and validity of the 281 completed questionnaires, Pearson correlation and a canonical correlation analyses were conducted using the nine dimensions of culture as predictors of strategy execution variables, to evaluate the multivariate shared relationship between the two variable sets.
\end{abstract}

Findings: The findings indicate that the dimensions of organisational culture have a variation of strong, medium and weak associations with the dimensions of strategy execution. Achievement orientation was found to have the highest effect on strategy execution dimensions and the future planning orientation the second highest.

Research limitations/implications: The major limitation was that the population was represented by one large organisation in the South African FMCG industry, thereby excluding other companies in this country and the results may not necessarily be generalised to other populations. Future studies could include more industries and countries.

Practical implications: This study provides evidence that company management must place considerable emphasis on developing organisational culture dimensions that have a positive impact on strategy execution.

Originality/value: The study reveals that achievement and future planning orientated cultures have a significant influence on strategy execution.

Keywords: Organisational Culture; Strategy Execution; Dimensions; Achievement Culture; Hofstede

\section{INTRODUCTION}

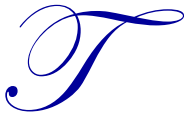

he rapid rate of globalisation makes maintaining competitive advantage imperative for organisational survival. A strong organisational culture has almost become as important as business strategy for maintaining this competitive edge. Organisational culture refers to a set of beliefs, values, norms and assumptions shared by members of an organisation (Gregory, Harris, Armenakis \& Shook, 2009). The process of converting strategy into action is referred to as strategy execution. Bossidy, Charan and Burck (2011) define execution as a distinct set of behaviours and techniques organisations need to master in order to have competitive advantage. Strategy execution involves the use of frameworks to achieve an organisation's overall objective (MacLennan, 2010).

Although there is no scarcity of literature verifying the effects of organisational culture on performance, ranging from employee satisfaction, financial performance and market performance to innovation (Hogan \& Coote, 2014; Prajogo 
\& McDermott, 2011), the impact of such variation on strategy execution remains relatively unexplored. This research is therefore aimed at examining the effect of organisational culture on strategy execution, and determining related implications.

Organisations with strong cultures exude open communication and empower employee decision-making, thereby creating a favourable working atmosphere (Schneider, Ehrhart \& Macey, 2013). However, creating this kind of organisational culture requires leadership to understand the values, norms and assumptions that support culture and its effect on organisational performance, such as cohesion, satisfaction and strategy execution, among other factors (Hoppe \& Eckert, 2015; Kargas, Varoutas \& Nisar, 2015).

Organisational performance is demonstrated by the achievement of the organisation's goals or key performance indicators (Heesen, 2015) which measure how well the organisation is executing its strategy into actions that grow and sustain it. It is theorised, therefore, that due to the integrated nature of organisational performance and strategy execution, organisational culture is essential for strategy execution (Zheng, Yang \& McLean, 2010) and should be considered as an impetus for strategy execution.

Several studies have aimed to develop models that test the effect of organisational culture on organisational performance (Cameron \& Quinn, 2006). In the strategic management literature, evaluations of how well organisations achieve their goals and execute their strategies include measures of healthy financial performance, good sales outcomes, high innovation and happy employees (Yesil \& Kaya, 2013). However, there is limited research into the effects of culture on strategy implementation (Ahmadi, Alamzadeh, Daraei \& Akbari, 2012). The objective of this study is to address this gap in the literature by investigating the relationship between organisational culture and strategy execution.

Organisations unable to understand how their cultures affect their ability to execute strategy are usually setting themselves up for disappointment or even failure (MacCormack, Dunn \& Kemerer, 2012). This research sets out to understand which types of cultures enable organisations to execute their strategic objectives and the effect of culture on strategy execution. Please see footnote below ${ }^{1}$

\section{THEORETICAL BACKGROUND}

\section{Strategy Execution}

A good strategy is directly proportionate to a company's long-term sustainability. A winning strategy is equated to an organisation's external environment, its strengths, the competitive capabilities of its internal resources, its ability to sustain a competitive advantage, and its performance regardless of economic and market fluctuations/changes (Miller, Eisenstat \& Foote, 2002). Strategy execution is the process through which the organisation indirectly manipulates the pattern of resource and market interactions, within its environment, to achieve its overall goals (MacLennan, 2010).

Strategy execution must be integrated into the company's strategy, goals, and, most importantly, culture. It is also critical for leaders of the organisation to be deeply involved with the execution, thus setting an example of accountability. Strategies fail when managers consider execution from a tactical perspective and delegate it to subordinates.

There are a number of strategy execution frameworks that have become widely-used management tools. For example, McKinsey's "7-S model” describes seven key factors - strategy, structure, systems, skills, staff, style and shared values - considered critical for effective strategy execution (Kaplan, 2005). Norton and Kaplan's balanced scorecard (BSC) model is a quantification tool for strategy execution which organises performance objectives and measures into four perspectives: financial, customer, internal process as well as learning and growth (Kaplan, 2012).

Most organisations try to fix execution problems by changing their organisational design or restructuring, which does not address the root cause of the failure to execute on strategy (Neilson, Martin \& Powers, 2008). Failure to execute

${ }^{1}$ The article is based on a research project conducted by Melissa Reddy (Reddy, 2016). 
on strategy can be addressed by ensuring employees are accountable for their roles and decision-making, as well as provided with the information needed to make good decisions (Neilson, Martin \& Powers, 2008). Several factors contribute to a company's success or failure during strategy execution; however, some factors have a greater impact than others (Patten, 2015). The researchers summarised the key dimensions of strategy execution identified in the literature to inform the current study.

Recent literature has migrated from a resource-based to a dynamic capabilities view (Klein, 2011). Dynamic capabilities refer to an organisation's ability to incorporate, build and redistribute internal and external competences to address fast-changing environments (Li \& Liu, 2014). An organisation's culture can be regarded as both an internal resource and a dynamic capability. Culture has a potential strategic value since it is regarded as a complicated internal social phenomenon that is difficult to replicate and has unique characteristics or dimensions. Organisational culture has a positive relationship with organisational performance and hence strategy execution (Yesil \& Kaya, 2013) and deserves attention as an important construct in the current study.

\section{Organisational Culture}

There are two schools of thought when it comes to the impact of organisational culture on performance and strategy execution, though research is fairly limited. The first is that there are particular dimensions of culture which are linked to performance (Cheung, Wong \& Lam, 2012) and strategy execution; the second is that certain types of organisational culture are linked to improved performance and strategy execution (Ahmadi et al. 2012).

Culture influences employee attitudes and behaviour as they are guided by its values, norms and assumptions (Gregory et al. 2009; Nayak \& Barik, 2013). Management's decisions about organisational policy, which includes the implicit rules and expectations of organisational behaviour, define the culture of the organisation (Nayak \& Barik, 2013). Organisational culture therefore allows for integration between organisation members so they know how to relate to one another and assists the organisation to adapt to its external environment (Chen, Hen \& Meindl, 1998).

The culture of the organisation shapes and coordinates employee behaviour to encourage commitment to achieve organisational goals (Aryasri \& Aijaz, 2013). The appropriate cultural values help organisations rapidly respond to customer needs and wants, or competitor actions, therefore making it strategically relevant (Linnenluecke \& Griffiths, 2010).

Culture in an organisation comprises three levels. At the surface level are the visible artefacts - all things one can hear, see and observe by watching other members of the organisation. At a deeper level, values and beliefs are expressed; these are not observable but can be discerned from how people explain and justify their actions. At the core level, some values become so deeply embedded in a culture that they can be defined as basic assumptions. These are less open to question, and guide the language and social interaction of organisational members (Cheung, Wong, \& $\mathrm{Wu}, 2011$ ). Values therefore, can be used as a subtle mechanism through which influence can be exercised by senior management (Mumford, Scott, Baddis \& Strange, 2002). Schein (1992), a leading researcher on the differentiating factors between the multiple layers of culture within an organisation, believes that values determine observed patterns of behaviour and underlie norms and artefacts.

Hofstede (1984) collected and analysed data from IBM, a large multinational corporation, across forty different countries. His research found that organisations are cultural-bounded even though they may lie in different locations worldwide. Additionally, four culture dimensions were identified to analyse cultural values in different countries, namely power distance, uncertainty avoidance, individualism and masculinity (Wu, 2006).

Hofstede's (Minkov \& Hofstede, 2011) approach to cultural dimensions has been met with contention by some academics who still believe that culture must be treated as a package. However, Hofstede's work has also inspired numerous other studies, the most popular of which is the GLOBE research program (House, Hanges, Javidan, Dorfman \& Gupta, 2004) which expanded Hofstede's five cultural dimensions to nine (House et al. 2001). These were the founding principles used for the culture items in the GLOBE questionnaire, which also distinguishes between cultural practices and cultural values (House, Javidan, Hanges \& Dorfman, 2002). This questionnaire was used in the current study. 
The nine cultural dimensions in the GLOBE research programme, identified by House et al. (2001, 2004), are:

- Uncertainty Avoidance: the extent to which members of an organisation rely on social norms, rituals and bureaucratic practices as the means to avoid uncertainty and unpredictability of future events;

- Power Distance: the degree to which members of an organisation understand and expect that power in an organisation should be unequally shared;

- Collectivism I: Societal Collectivism refers to the degree to which organisational practices and behaviour encourage team work and reward, or the collective distribution of resources;

- Collectivism II: In-Group Collectivism refers to the degree to which members of an organisation express pride, loyalty, cohesiveness and commitment in their organisations;

- Gender Egalitarianism: the extent to which an organisation minimises gender role differences and gender discrimination;

- Assertiveness: the degree to which members in an organisation are assertive, confrontational and aggressive in work and social relationships.

- Future Orientation: the degree to which members in an organisation engage in behaviours which delay instant gratification and focus on future-oriented behaviour such as planning and investing in the future;

- Achievement Orientation: the extent to which an organisation supports and rewards group members for striving for continuous improvement and excellence in performance;

- Humane Orientation: the degree to which members in an organisation support and reward individuals for being fair, altruistic, friendly, generous, caring, and kind to others.

This study hypothesised that each of the nine cultural dimensions influences strategy execution dimensions; for example: the cultural dimension of achievement orientation refers to the extent to which an organisation prides itself on success, aims for highest standards in performance and supports the implementation of challenging goals which encourage employees to stretch themselves to excel (House et al. 2001).

Hypotheses for this study include the relationship of each cultural dimension with each strategy execution dimension and these relationships are summarised as follows:

H01: There is no association (variables are independent) between culture dimensions (uncertainty avoidance, gender egalitarianism, assertiveness, institutional collectivism, in-group collectivism, humane orientation, future orientation, achievement orientation and power distance) and the strategy execution dimensions of information sharing, leadership, reward, structure, employee commitment, as well as coordination.

HA1: There is an association between the culture dimensions (uncertainty avoidance, gender Egalitarianism, assertiveness, institutional collectivism, in-group collectivism, humane orientation, future orientation, achievement orientation and power distance) and the strategy execution dimension of information sharing, leadership, reward, structure, employee commitment, as well as coordination.

\section{METHOD}

As the aim of the research was to describe the effect of organisational culture on strategy execution, the research methodology used was of a descriptive nature. The research design was therefore a quantitative design to investigate whether the relationship between organisational culture and strategy execution is statistically significant for a given population, i.e. the data obtained was numerical in nature (Saunders \& Lewis, 2012). A positivism philosophy, using deduction as the approach, was used, with a survey strategy chosen as a mono method. This approach was taken as the intent of the research study was to add more value to the existing body of knowledge and does not specifically involve the development of theory. Due to the quantitative nature of the study the survey method was selected as the most suitable research strategy (Saunders \& Lewis, 2012). As the researcher was able to obtain a complete list of the members of the population, the population was also the sampling frame (Saunders \& Lewis, 2012). The unit of analysis for the study was management of the organisation. 


\section{Research Procedure and Participants}

The research was conducted within a large South African company in the FMCG industry. Through its diverse portfolio of product offerings the organisation has many operations spread across multiple geographical regions within South Africa. The company was founded in 1820 and is entering a new, exciting period in its journey. The past couple of years have seen a series of changes as the company moved from its traditional milling and baking business into sugar confectionery. The strategic intent is to be a leading FMCG player in chosen geographies. The research was conducted within the executive, senior, middle and first line management of this company, as it is these four lines of management that are predominantly responsible for cascading and executing strategy within its several business units. The managers are geographically spread across South Africa, within all operations and headquarters. There are over 5000 employees within the company, with a management complement of 600 people. The survey questionnaires were distributed to all 600 managers at the FMCG company via an electronic system known as "Survey Monkey" ensuring anonymity for participants. The probability of each case being selected from the sampling frame was equal and known, making the sampling technique a probability sampling technique (Saunders, Lewis \& Thornhill, 2009). The population was composed of 600 employees at management level from all areas of the FMCG company. 281 responses were received, representing a response rate of $48 \%$.

\section{Measures}

The questionnaire consisted of three sections. The first section asked biographical questions. Section two comprised the scale for organisational culture developed by House et al. (2004), who found an overall Cronbach alpha of 0.77 proving that the survey is reliable. The GLOBE nine cultural dimensions are: power distance, uncertainty avoidance, humane orientation, collectivism (institutional and in-group), assertiveness, gender egalitarianism, future orientation and performance orientation (Minkov \& Blagoev, 2012). The GLOBE questionnaire organised 18 items into the nine parts mentioned above and is measured on a Likert scale of 1 to 7 . For the purposes of this study the questionnaire was modified to a Likert scale of 1 to 5 . This was considered to be more manageable and easier for the participants to understand. Items include, "At the organisation, the pay and bonus system is designed to maximise individual interests" (on the one end of the continuum of five points on the Likert scale), or "At the organisation, the pay and bonus system is designed to maximise collective interests" (on the other end)."

The strategy execution research instrument consisted of 43 items measuring nine constructs, most through five items each. The nine constructs used a five-point Likert scale ( $1=$ strong disagreement to $5=$ strong agreement). The constructs and items were built from surveys developed by O'Reilly, Caldwell, Chatman, Lapiz, and Self (2010) for the items on leadership, for example, "Our leaders clearly articulate the strategy"; Crittenden \& Crittenden (2008) for items on coordination, for example, "We foster company collaboration"; Hrebiniak (2005a) for items on information sharing, such as, "We willingly share information with others"; Parnell (2008) for items on employee commitment, for instance, "I am committed to seeing our organisational strategy is effectively implemented"; Krishnakumar (2015) for items on change, like "Our organisation is in a state of readiness to accept the changes that would be resulted by the strategy"; and Shah (2005) for items on rewards, for example, "Our rewards motivate us to contribute our best". Competence items were derived from Pryor, Anderson, Toombs and Humphreys (2007) and include, "We have competencies that build a competitive advantage". With regards to structure (Olson, Slater \& Hult, 2005), items include, "Our organisational structure encourages clear accountability for delivery of strategic initiatives". Finally, items for assessing performance include, "We have accomplished our goals" (Schneier, Shaw \& Beatty, 1991).

The questionnaire was pilot tested by sending it out to three individuals prior to the official data collection process. The purpose was to perform pre-testing, whereby spelling, grammar, ease of understanding and use, as well as functionality of the system, were tested (Rothgeb, 2008). Respondents reported that the organisational culture section did not need the construct headings, as this made the survey monotonous and it was evident what was being questioned. The construct headings were removed but the item order remained the same to ensure some level of consistency with the original GLOBE organisational culture survey. Once the issues from the pilot were addressed, the questionnaire was sent out to the entire population.

Data in this survey was collected via the Internet by emailing a hyperlink to the web survey. This method was chosen since online collection of data allows for it to be collated without the need for recapture. A cut-off date of four weeks 
was given for the survey, and the total number of responses for the FMCG company was 339, 41 of which were incomplete.

\section{Sample Characteristics}

The majority of respondents (35.6\%) were between the ages of 31 and 40 years. This was followed by the 41 to 50 years age category, which constituted $29.5 \% .16 .7 \%$ of respondents were 30 years or less. In this sample, $65.1 \%$ were male and $34.9 \%$ female. The largest management group to participate in this research was junior management $(45.9 \%)$, followed by middle management (34.5\%), then senior management (14.95\%) and executive management (4.6\%).

Respondents with tenure of eight or more years constituted $32.74 \%$. Those with tenure of three to seven years constituted $42.0 \%$ and respondents with tenure up to two years $25.27 \%$ of the sample. The majority of respondents had been in management for five years or less, followed by 15 years and more, and six to 10 years. The majority had been employed by the organisation for between three and seven years. Most $(69.8 \%)$ were involved in strategy implementation, while $30.2 \%$ were not. Of the 85 respondents not involved in strategy implementation, the majority (72.29\%) were junior management. The remaining $21.18 \%$ not involved in strategy implementation were middle management.

\section{Reliability and Validity of Data}

To determine the suitability of factor analysis, a Kaiser-Meyer-Olkin (KMO) and a Bartlett test for sphericity were conducted (Sekaran, 2005; Hair, Black, Babin, Anderson, \& Tatham, 2006). KMO measures sampling adequacy which compares the sizes of the observed correlation coefficients to the sizes of the partial correlation coefficients for the sum of analysis variables (Exner, 2013). The Bartlett test is an indication of the strength of the relationship among variables (Pandey, 2016). For acceptability the KMO test should be higher than 0.6. The KMO index for sampling adequacy is .936, and for culture it is .844 . The test of sphericity by the Bartlett test was statistically significant: ChiSquare 8528.353 and for culture, 1412.818 . Both are significant.

Eigenvalue shows the number of extracted factors whose sum should be equal to the number of items which are subjected to factor analysis (Chetty \& Datt, 2015). The extraction sums of squared loadings was the preferred method of extraction, as it is automatic and not forced (Chetty \& Datt, 2015). When applied to the strategy execution analysis, it extracted ten components. $60 \%$ is explained by six components and for $70 \%$, ten components were extracted. The eigenvalue for component one was 17.42 and explained $40.5 \%$ of the variance. The remaining nine components explained $59.5 \%$ of the variance.

The scree plot graph of the eigenvalues shows that the point at which the curve starts to flatten is after the tenth factor, the "point of interest" (Chetty \& Datt, 2015), implying that ten components should be retained. Thus, the eigenvalues over 1 for all ten factors are considered. The research identifies the ten factors as: Information sharing (InfoSh); Leadership (Lead); Performance (Per); Rewards (Rew); Structure (Str); Employee commitment 1 (EmpCom1) (items were presented in the negative); Employee commitment 2 (EmpCom2) (items were presented in the positive); Change (Cha); Coordination (Coord) and Competence (Comp). 
Table 1. Strategy Execution Dimensions' items with Exploratory Factor Analysis (EFA) and Reliability

\begin{tabular}{|c|c|c|c|c|}
\hline No & $\begin{array}{l}\text { Strategy Execution } \\
\text { Dimension }\end{array}$ & $\begin{array}{l}\text { Cronbach } \\
\text { Alpha }\end{array}$ & Items & $\begin{array}{r}\text { EFA } \\
\text { value }\end{array}$ \\
\hline \multirow{10}{*}{1} & \multirow{10}{*}{$\begin{array}{l}\text { Information } \\
\text { Sharing (InfoSh) }\end{array}$} & \multirow{10}{*}{.898} & We Believe That Our Sources Of Information Are Reliable & .761 \\
\hline & & & We Willingly Share Information Or Knowledge With Others & .738 \\
\hline & & & Our Information Reaches People Who Need It Within The Organisation & .682 \\
\hline & & & $\begin{array}{l}\text { We Divide Tasks And Activities Among And Across Business Units In } \\
\text { The Organisation }\end{array}$ & .635 \\
\hline & & & $\begin{array}{l}\text { Employees Understand And Evaluate The Usefulness Of Available } \\
\text { Information }\end{array}$ & .568 \\
\hline & & & $\begin{array}{l}\text { Our Managers Trust Information Generated From Sources Outside Their } \\
\text { Own Departments }\end{array}$ & .562 \\
\hline & & & $\begin{array}{l}\text { Employees Understand What The Changes Will Be And Why They Are } \\
\text { Being Undertaken }\end{array}$ & .520 \\
\hline & & & We Foster Company Collaboration & .510 \\
\hline & & & We Have Access To Adequate Resources/Tools & .441 \\
\hline & & & We Focus On Improving The Capability Base In The Organisation & .383 \\
\hline \multirow{5}{*}{2} & \multirow{5}{*}{$\begin{array}{l}\text { Leadership } \\
\quad \text { (Lead) }\end{array}$} & \multirow{5}{*}{.925} & Our Leaders Provide A Compelling Vision & .790 \\
\hline & & & $\begin{array}{l}\text { Our Leaders Provide Measurable Objectives For Implementing The } \\
\text { Vision }\end{array}$ & .784 \\
\hline & & & Our Leaders Personally Inspire And Motivate For Us To Change & .739 \\
\hline & & & Our Leaders Clearly Articulate The Strategy & .739 \\
\hline & & & Our Leaders Respond Effectively To Resistance To Change & .567 \\
\hline \multirow{5}{*}{3} & \multirow{5}{*}{$\begin{array}{l}\text { Performance } \\
\quad \text { (Perf) }\end{array}$} & \multirow{5}{*}{.937} & We Have Accomplished Our Goals & .834 \\
\hline & & & We Have Adapted Our Business To Maximise Our Goals & .801 \\
\hline & & & We Have Done What We Have Planned To & .734 \\
\hline & & & We Have Executed Our Strategy Well & .715 \\
\hline & & & We Have The Best People And Capability To Sustain Our Success & .477 \\
\hline \multirow{5}{*}{4} & \multirow{5}{*}{$\begin{array}{l}\text { Rewards } \\
\text { (Rew) }\end{array}$} & \multirow{5}{*}{.915} & Our Rewards Motivate Us To Contribute Our Best & .847 \\
\hline & & & $\begin{array}{l}\text { Our Rewards Motivate Us To Go The Extra Mile To Implement Strategic } \\
\text { Decisions To The Best Of Our Abilities }\end{array}$ & .840 \\
\hline & & & $\begin{array}{l}\text { Our Organisation Rewards Us For The Successful Implementation Of The } \\
\text { Strategic Plan }\end{array}$ & .711 \\
\hline & & & $\begin{array}{l}\text { We Recognise Commitment And Excellence In Strategy Execution In } \\
\text { Both Teams And Individuals }\end{array}$ & .644 \\
\hline & & & $\begin{array}{l}\text { We Celebrate Strategic Execution Success Publicly/Openly Across All } \\
\text { Business Units }\end{array}$ & .639 \\
\hline \multirow{6}{*}{5} & \multirow{6}{*}{$\begin{array}{l}\text { Structure } \\
\quad(\mathrm{Str})\end{array}$} & \multirow{6}{*}{.884} & $\begin{array}{l}\text { Our Organisational Structure Nurtures The Few Critical Competencies } \\
\text { For Competitive Advantage }\end{array}$ & .761 \\
\hline & & & $\begin{array}{l}\text { Our Organisational Structure Meets The Requisite Demands Of The } \\
\text { Strategy. For Example, If Your Strategy Is To Be A Low Cost Provider - } \\
\text { A Structure That Fosters Low Cost Should Be Implemented }\end{array}$ & .740 \\
\hline & & & $\begin{array}{l}\text { Our Organisational Structure Encourages Both Teamwork And } \\
\text { Individuality }\end{array}$ & .614 \\
\hline & & & $\begin{array}{l}\text { Our Organisational Structure Encourages Clear Accountability For } \\
\text { Delivery Of Strategic Initiatives }\end{array}$ & 609 \\
\hline & & & $\begin{array}{l}\text { Our Leaders In The Organisation Seek To Manage The On-Going Change } \\
\text { Portfolio, Conflict Resolution, Resources And Interdependencies }\end{array}$ & .568 \\
\hline & & & $\begin{array}{l}\text { Our Organisation Is In A State Of Readiness To Accept The Changes That } \\
\text { Would Be Resulted By The Strategy }\end{array}$ & .535 \\
\hline \multirow{3}{*}{6} & \multirow{3}{*}{$\begin{array}{l}\text { Employee } \\
\text { commitment1 } \\
(\text { EmpCom1) }\end{array}$} & \multirow{3}{*}{.769} & $\begin{array}{l}\text { I Don't Concern Myself With Implementing Strategies If They Are Not } \\
\text { Beneficial To My Department> }\end{array}$ & -.825 \\
\hline & & & $\begin{array}{l}\text { I Tend To Be Less Concerned With Working Together And More } \\
\text { Concerned With Competing To Be Best }>\end{array}$ & -.815 \\
\hline & & & I Don't Worry About Implementing Strategy; I Just Do My Job> & -.798 \\
\hline
\end{tabular}


Table 2 continued

\begin{tabular}{|c|c|c|c|c|}
\hline No & $\begin{array}{l}\text { Strategy Execution } \\
\text { Dimension }\end{array}$ & $\begin{array}{l}\text { Cronbach } \\
\text { Alpha }\end{array}$ & Items & $\begin{array}{c}\text { EFA } \\
\text { value }\end{array}$ \\
\hline \multirow{3}{*}{7} & \multirow{3}{*}{$\begin{array}{c}\text { Employee } \\
\text { commitment1 } \\
(\text { EmpCom2) }\end{array}$} & \multirow{3}{*}{618} & $\begin{array}{l}\text { I Believe That My Organisation Is Most Successful When Everyone } \\
\text { Works To Implement A Common Strategy }\end{array}$ & .720 \\
\hline & & & We Have Competencies That Build A Competitive Advantage & .525 \\
\hline & & & $\begin{array}{l}\text { I Am Committed To Seeing Our Organisational Strategy Is Effectively } \\
\text { Implemented }\end{array}$ & .457 \\
\hline \multirow[t]{2}{*}{8} & \multirow[t]{2}{*}{$\begin{array}{l}\text { Change } \\
\text { (Ch) }\end{array}$} & \multirow{2}{*}{$.478^{*}$} & $\begin{array}{l}\text { Our Organisation Can Adapt To Market Conditions By Exiting A } \\
\text { Declining Business That Is Inhibiting Strategic Goals }\end{array}$ & .745 \\
\hline & & & $\begin{array}{l}\text { Our Organisation Can Adapt To Market Conditions By Moving Funds And } \\
\text { People Where It Is Most Needed To Execute The Strategy }\end{array}$ & .602 \\
\hline \multirow[t]{2}{*}{9} & \multirow{2}{*}{$\begin{array}{l}\text { Coordination } \\
\text { (Coor) }\end{array}$} & \multirow{2}{*}{.691} & We Use Teams Only From Within My Own Business Unit & .819 \\
\hline & & & We Use Of Cross-Functional Teams/Groups From Other Business Units & .615 \\
\hline \multirow[t]{2}{*}{10} & \multirow{2}{*}{$\begin{array}{l}\text { Competence } \\
\text { (Comp) }\end{array}$} & \multirow{2}{*}{$.367^{*}$} & We Use Informal Communication (Ie. Person-To-Person Contact) & .696 \\
\hline & & & We Have A Few Competencies That Are Distinctive & .657 \\
\hline
\end{tabular}

>statements in the negative; *Since Cronbach Alphas were low, these constructs were not included in the subsequent analyses; Factor analysis: extraction method: principal component analysis, rotation method: varimax with Kaiser normalization, rotation converged in 8 iterations.

Following on from the factor analysis, the main factors (or constructs) for organisational culture and strategy execution were tested in terms of Cronbach's alpha. An item analysis was conducted, where the correlation with the total construct of each item was measured, and the effect of deleting each variable was assessed. House et al. (2004), founders of the GLOBE culture survey, tested reliability of their questionnaire and found an overall high Cronbach alpha of .77 on all nine main constructs. In instances where the Cronbach alpha score increased considerably after removing the item, they were removed from the analysis. In instances where the Cronbach alpha score was low, these items were also removed from the analysis. For example, when the item, "In this organisation, job requirements and instructions are clearly defined so employees know what is expected of them" and "In this organisation, men are encouraged to participate in professional development activities more than women", are deleted, the Cronbach alpha score increases significantly to .692 . Exploratory factor analysis showed the first factor in the cultural dimensions analysis has high weighting of items as a combination of assertiveness, power distance and achievement and with high Cronbach alpha of .839. However, as the initial nine factors in the House et al. (2004) study had high Cronbach alphas and acceptable validity from their factor analysis, these factors were retained in the current study.

The main factors (information sharing, leadership, performance, rewards, structure, and employee commitment 1) had fairly high Cronbach alphas (reliability) as the table illustrates. The employee commitment 2 factor had questionable reliability, however. The change and competence factors were regarded as unacceptable and therefore not included in the subsequent analysis.

The data was analysed using Statistical Package for Social Science (SPSS) version 23. The measure of the association for examining the relationship between the sub-dimensions of culture (Minkov \& Blagoev, 2012) and strategy execution was performed using Pearson Correlation ( $r$ ), a measure of the strength and direction of association that exists between two variables. The strength was analysed based on guidelines by Pallant (2010). The $r$ value of $<0.29$ indicates a weak relationship, $0.3-0.49$ indicates a medium relationship and $\geq 0.5$ indicates a strong relationship.

As the Pearson correlation test is a uni-variant statistical test (Bujang \& Baharum, 2016), canonical correlation analysis was also performed to identify the measure of association among two sets of variables - that is, the sub-dimensions of the organisational culture and strategy execution. Canonical correlation is appropriate in the same situations as multiple regression would be, but where there are multiple inter-correlated outcome variables and it determines a set of canonical variants and orthogonal linear combinations of the variables within each set that best explain the variability both within and between sets (Bruin, 2016).

\section{RESULTS}

The Pearson correlation table shows that for the nine organisational culture dimensions and information sharing there are seven statistically significant relationships: uncertainty avoidance, assertiveness, in-group collectivism, humane 
orientation, future orientation, achievement orientation and power distance (House et al. 2001) with information sharing. Two relationships, namely gender egalitarianism and institutional collectivism with information sharing, are not statistically significant.

The relationships between in-group collectivism, humane orientation, achievement orientation, power distance and information sharing are strong, whereas the others are either of weak or of medium strength.

Limited space permits only a summary of the Pearson correlations between all culture and dimensions of strategy execution in the table below. The complete tables are available from the researchers on request.

Table 2. Summary of Pearson correlations

\begin{tabular}{|c|c|c|c|c|c|c|c|c|}
\hline \multirow{2}{*}{ Culture } & \multicolumn{8}{|c|}{ Strategy Execution Dimensions } \\
\hline & 1 InfoSh & 2 Lead & 3 Rew & 4 Perf & $5 \mathrm{Str}$ & 6 EmpCom1 & 7 EmpCom2 & 8 Coord \\
\hline A UncAv & $.365^{* *}$ & $.351^{* *}$ & $.240^{* *}$ & $.288^{* *}$ & $.358^{* *}$ & $.121^{*}$ & $.234^{* *}$ & .068 \\
\hline \multirow{2}{*}{ B GenEg } & .098 & $.148^{*}$ & .118 & .052 & $.141^{*}$ & .049 & $.137^{*}$ & $.225^{* *}$ \\
\hline & .108 & .015 & .053 & .400 & .021 & $.321^{* *}$ & .025 & .086 \\
\hline C Ass & $.268^{* *}$ & $.265^{* *}$ & $.336^{* *}$ & $.297^{* *}$ & $.249^{* *}$ & $.155^{*}$ & .102 & $-.169^{* *}$ \\
\hline \multirow[t]{2}{*}{ D InstCol } & -.088 & -.083 & -.054 & -.053 & -.067 & $-.195^{* *}$ & -.038 & .006 \\
\hline & .150 & .175 & .382 & .388 & .276 & .001 & .534 & $.331^{* *}$ \\
\hline E InCol & $.528^{* *}$ & $.566^{* *}$ & $.525^{* *}$ & $.433^{* *}$ & $.488^{* *}$ & $.282^{* *}$ & $.308^{* *}$ & $.328^{* *}$ \\
\hline F HumOr & $.586^{* *}$ & $.532^{* *}$ & $.494^{* *}$ & $.487^{* *}$ & $.416^{* *}$ & $.257^{* *}$ & $.322^{* *}$ & $.312^{* *}$ \\
\hline G FutOr & $.476^{* *}$ & $.440^{* *}$ & $.454^{* *}$ & $.416^{* *}$ & $.399^{* *}$ & $.237^{* *}$ & $.318^{* *}$ & $.419^{* *}$ \\
\hline $\mathrm{H}$ AcOr & $.692^{* *}$ & $.686^{* *}$ & $.691^{* *}$ & $.622^{* *}$ & $.574^{* *}$ & $.385^{* *}$ & $.451^{* *}$ & $.363^{* *}$ \\
\hline I PoD & $.568^{* *}$ & $.595^{* *}$ & $.536^{* *}$ & $.486^{* *}$ & $.511^{* *}$ & $.288^{* *}$ & $.305^{* *}$ & .068 \\
\hline \multirow{2}{*}{\multicolumn{9}{|c|}{$\begin{array}{l}\text { Note: }{ }^{* *} \text {. Correlation is significant at the } 0.01 \text { level (2-tailed } \\
\text { Highlighted cells indicate a strong significant relationship. }\end{array}$}} \\
\hline & & & & & & & & \\
\hline \multicolumn{9}{|c|}{$\begin{array}{l}\text { Columns of Strategy execution dimensions: } 1 \text { Information sharing (InfoSh); } 2 \text { Leadership (Lead); } 3 \text { Performance (Per); } 4 \text { Rewards (Rew); } 5 \\
\text { Structure (Str); } 6 \text { Employee commitment } 1 \text { (EmpCom 1); } 7 \text { Employee commitment } 2 \text { (EmpCom2); } 8 \text { Coordination (Coord); } \\
\text { Rows of Culture dimensions: A Uncertainty Avoidance (UncAv); B Gender Egalitarianism (GenEg); C Assertiveness (Ass); D Institutiona } \\
\text { Collectivism (InstCol); E In-group Collectivism (InCol); F Humane Orientation (HumOr); G Future Orientation (FutOr); H Achievemen } \\
\text { Orientation (AcOr); I Power Distance (PoD) }\end{array}$} \\
\hline
\end{tabular}

Interestingly, with regards to the strategy execution dimension of leadership, the same pattern of relationships with information sharing were found, in terms of their relative strengths. However, the relationship between leadership and gender egalitarianism is, in fact, a significant and weak relationship.

With regards to the strategy execution dimension of rewards, gender egalitarianism and institutional collectivism do not show a significant relationship, aligned with information sharing. In-group collectivism, achievement orientation and power distance have strong relationships with rewards; however, unlike with information sharing and leadership, rewards does not have a strong significant relationship with humane orientation, but is of medium strength at .494. Two relationships, gender egalitarianism and institutional collectivism with performance, are not statistically significant. Achievement orientation and performance indicate a strong relationship.

The Pearson correlation table for the nine culture dimensions and structure suggests there are eight statistically significant relationships: uncertainty avoidance, gender egalitarianism, assertiveness, in-group collectivism, humane orientation, future orientation, achievement orientation and power distance, and one relationship, namely institutional collectivism with structure, that is not statistically significant. Two strong positive associations between achievement orientation, power distance and structure exist.

The relationships with employee commitment 1 are significant, except for gender egalitarianism, and there are no strong relationships. The relationship with achievement orientation, however, is of medium strength. With regards to employee commitment 2, the results suggest there are seven statistically significant relationships and two, assertiveness and institutional collectivism with employee commitment 2, that are not statistically significant. There are no strong relationships. Only two relationships are not statistically significant with coordination: uncertainty avoidance and assertiveness, and there are no strong relationships. 


\section{Overall effect of Culture on Strategy Execution}

A canonical correlation analysis was conducted using the nine dimensions of organisational culture (House et al. 2001) as predictors of the eight strategy execution variables to evaluate the multivariate shared relationship between the two variable sets (i.e. culture and strategy execution). The eigenvalues and canonical correlations analysis yielded two functions with squared canonical correlations (R2c) of .74523; .17098; .07454; .06099;.02560;.01821;.00536 and .001920 for each successive function. The first canonical correlation coefficients and the eigenvalues of the canonical roots, show a correlation coefficient of .86326 with an explained variance of the correlation of $87.87 \%$ and an eigenvalue of 2.92503 . This indicates that the hypothesis is correct - generally, the standardised test scores and the aptitude test scores are positively correlated.

Collectively the full model across all functions is statistically significant using the Wilks's $\lambda=.17432$ criterion, $\mathrm{F}$ ( 72 , $1534.35)=7.094, p<.001$. Because Wilks's $\lambda$ represents the variance unexplained by the model, $1-\lambda$ yields the full model effect size in an $\mathrm{R}^{2}$ metric. The dimension reduction analysis tests the hierarchal arrangement of functions for statistical significance. As noted, the full model (Functions 1 to 8 ) is statistically significant, F $(72,1534.35)=7.09$, $\mathrm{p}<.001$ and the functions 2 to 8 are also statistically significant, $\mathrm{F}(56,1362.37)=1.78, \mathrm{p}<.001$. The functions 3 to 8,4 to 8,5 to 8,6 to 8,7 to 8 and 8 to 8 are all not statistically significant with all p value $>.05$. Given the effects for each function, only the first two functions were considered important in the context of the analysis, since they had a shared variance of $.916(.745+.171)$, which is $91.6 \%$. The univariate analysis shows that all eight strategy execution dimensions are statistically significant with $p$-value $<.001$, indicating that a single dimension, or a combination of the nine culture dimensions, predicted this relationship.

The regression equations for each dependent variable are offered separately. It is considered a post hoc test to enhance the interpretation of the canonical correlation analysis.

Table 3. Independent univariate tests $(\mathrm{N}=281)$

\begin{tabular}{l|c|c|c|c|c|c|c|c|c}
\hline $\begin{array}{c}\text { Culture } \\
\text { Dimensions }\end{array}$ & $\mathbf{1}$ InfSh & $\mathbf{2 ~ L e a d ~}$ & $\mathbf{3 ~ R e w}$ & $\mathbf{4}$ Perf & $\mathbf{5 ~ S t r}$ & $\mathbf{6}$ EmpCom1 & $\mathbf{7}$ EmpCom2 & $\mathbf{8 ~ C o o r d ~}$ \\
\hline A UncAv & $.001^{* *}$ & $.004^{* *}$ & .902 & .086 & $.001^{* *}$ & .895 & .059 & .145 \\
\hline B GenEg & .632 & .289 & .758 & .260 & .304 & $.000^{* *}$ & .176 & $.004^{* *}$ \\
\hline C Ass & .814 & .948 & $.031^{* *}$ & .166 & .719 & .706 & .110 & .235 \\
\hline D InstCol & $.014^{* *}$ & .051 & .144 & .140 & .159 & $.002^{* *}$ & .533 & $.009^{* *}$ \\
\hline E InCol & .085 & $.001^{* *}$ & $.013^{* *}$ & .587 & $.011^{* *}$ & .189 & .666 & .123 \\
\hline F HumOr & $.000^{* *}$ & .077 & .262 & $.021^{* *}$ & .873 & .938 & .230 & .310 \\
\hline G FutOr & .055 & .658 & .122 & .140 & .454 & .856 & .151 & .113 \\
\hline H AcOr & $.000^{* *}$ & $.000^{* *}$ & $.000^{* *}$ & $.000^{* *}$ & $.000^{* *}$ & $.000^{* *}$ & $.000^{* *}$ & $.001^{* *}$ \\
\hline I PoD & .066 & $.001^{* *}$ & $.029^{* *}$ & .133 & $.005^{* *}$ & .624 & .904 & .204 \\
\hline
\end{tabular}

**. Correlation is significant at the 0.05 level; The shaded row shows significance on all dimensions.

The results show that achievement orientation is statistically significant across all dimensions of strategy execution. This means it has the greatest impact.

A regression analysis on the control variables for each dimension of strategy execution was conducted. The first model in the table below shows the relationship between the predictors, namely the dimensions of culture: Power Distance, Assertiveness, Uncertainty Avoidance, Future Orientation, In-group Collectivism, Humane Orientation, Achievement Orientation and the dependent variable, namely information sharing (a). The next models introduce the control variables, namely management level in model 2, involvement in strategy execution as model 3 and finally, the description of type of strategy as model 4.

Variance explained is $\left(\mathrm{r}^{2}=.592\right)$, which means that $59.2 \%$ of the variance in the information sharing is explained by culture dimensions (a). Control variables have no influence on the relationships, since none are significant (Sig F change - p-values > .05), with the $\mathrm{R}^{2}$ change being $.000, .001(0.1 \%)$ and $.003(0.3 \%)$ for management level, strategy involvement and organisation strategy, respectively. These models were calculated for all strategy dimensions. Due 
to limited space, the results are summarised and the complete tables are available from the researchers on request. The summary table of the regression analysis appears below.

Management level positively influences the relationship between culture dimensions and leadership ( $p$-value $=.001$ and $\mathrm{r}^{2}$ change of $1.4 \%$ ). The other control variables have no influence on the relationship. With regards to rewards, the control variables have no influence on relationship between rewards and culture dimensions and likewise for performance and structure. Management level also has an influence on employee commitment 1 , with a p-value $=.009$ and $\mathrm{r}^{2}$ change of $1.9 \%$ as well as the other control variable: involvement in organisational strategy execution (with a $\mathrm{r}^{2}$ change of $1.4 \%, \mathrm{p}=.026$ ). Management level and organisation strategy thus positively influence the relationship between culture dimensions and employee commitment 1 . This influence does not exist, however, with regards to employee commitment 2 or coordination.

Table 4. Regression Analysis

\begin{tabular}{l|c|c|c|c|c|c|c|c|c|}
\hline \multicolumn{1}{|c|}{ Dimension } & R & R Square & $\begin{array}{c}\text { Adjusted R } \\
\text { Square }\end{array}$ & $\begin{array}{c}\text { Std. Error of } \\
\text { the Estimate }\end{array}$ & $\begin{array}{c}\text { R Square } \\
\text { Change }\end{array}$ & F Change & df1 & df2 & $\begin{array}{c}\text { Sig. F } \\
\text { Change }\end{array}$ \\
\hline 1 InfSh & .769 & .592 & .581 & .39929 & .592 & 53.911 & 7 & 260 & .000 \\
\hline 2 Lead & .764 & .584 & .571 & .543126 & .584 & 45.360 & 8 & 259 & .000 \\
\hline 3 Rew & .736 & .542 & .530 & .58557 & .542 & 44.006 & 7 & 260 & .000 \\
\hline 4 Perf & .669 & .447 & .432 & .52690 & .447 & 30.052 & 7 & 260 & .000 \\
\hline 5 Str & .660 & .436 & .419 & .50171 & .436 & 25.037 & 8 & 259 & .000 \\
\hline 6 EmpCom 1 & .516 & .266 & .240 & .54809 & .266 & 10.388 & 9 & 258 & .000 \\
\hline 7 EmpCom 2 & .486 & .236 & .216 & .59928 & .236 & 11.488 & 7 & 260 & .000 \\
\hline 8 Coord & .514 & .265 & .245 & .82154 & .265 & 13.365 & 7 & 260 & .000 \\
\hline
\end{tabular}

The table illustrates that the variance explained is $\mathrm{r}^{2}=.592$, thus $59.2 \%$ of the variance in the information sharing dimension is explained by culture dimensions and $58.4 \%$ of the variance in leadership is explained by culture dimensions. The other strategy execution dimensions have lower scores for the variance explained. For example, $54.2 \%$ of the variance in the rewards is explained by culture dimensions and $44.7 \%$ by the performance dimension. With regards to structure, $43.6 \%$ of the variance is explained by culture dimensions, whereas $26.6 \%$ of the variance in the employee commitment 1 is explained by culture dimensions, compared to $23.6 \%$ in the employee commitment 2. Only $26.5 \%$ of the variance in the coordination is explained by culture dimensions.

\section{DISCUSSION}

\section{Information Sharing}

For the sample group, there is a statistically significant correlation between seven of the nine organisational culture dimensions and the strategy execution dimension of information sharing; $59.2 \%$ is explained by the cultural dimension, with achievement orientation having the strongest relationship with information sharing. These findings support the literature; for example, complex strategies are founded on three principles, namely effective information sharing, coordination and cooperation (Hrebiniak, 2006; Patten, 2015); and effective information sharing within the organisation enables coordination, adapting to an ever-changing business landscape and defining the future state of the company (Sharifirad \& Ataei, 2012). Information sharing must be instituted across organisational business units as it is a vital ingredient for effective coordination.

This study confirms there is a definite association between organisational culture and the strategy execution dimension of information sharing. The Project Globe cultural dimensions have their own link to the strategy execution dimension of information sharing. For example, uncertainty avoidance concerns the resistance of risk and unexpected events by emphasising rules and norms (Minkov \& Blagoev, 2012). In an environment where the strategy, and execution thereof, requires less risk and more policy-making, effective information sharing between departments is needed to understand and inform the risk platforms and decision-making, leading therefore to a higher inclination to share information. 
In highly collectivistic organisations, information sharing between teams is the key ingredient for cohesion. In organisations orientated towards future planning, information sharing is vital for decision-making for the future. Humane orientated organisations likewise have a positive influence on the sharing of information. Achievement orientation has the highest influence on information sharing. In an achievement oriented firm, information sharing is required to measure and reward achievement, leading to even more information sharing. In organisations where power is unequally distributed, effective information sharing frameworks are needed to maintain balance.

\section{Leadership}

This study reveals a statistically significant correlation between eight of the nine organisational culture dimensions and the strategy execution dimension of leadership. Again, achievement orientation has the strongest influence, as well as power distance. These findings support the literature that shows the association between organisational culture and the strategy execution dimension of leadership. The literature, from an organisational culture perspective, posits organisational leadership as the ability of an individual to influence, inspire and empower others to contribute toward the effectiveness and success of the organisations of which they are members (House et al. 2001). Once organisational culture has been established and there is a definitive way in which the organisation does things, the overall organisational practices have a major impact on how leaders behave and what they do. Over time, successive leaders tend to change their behaviours and leadership styles to suit the organisational culture (Chatman \& Cha, 2003).

The literature on leadership, from a strategy execution perspective, posits that leadership must drive the organisation to execution success. Leaders must encourage employees to take ownership of, and show commitment to, the execution process. Leadership's decision on the strategy execution process generally affects how employees respond to any strategy execution challenges. Leaders who are self-seeking and delay decisions for their own interests tend to encourage staff to look only at their own areas and not focus on the strategy execution of the organisation as a whole (Hrebiniak, 2005b).

This study confirms a definite association between organisational culture and the strategy execution dimension of leadership. In highly collectivistic organisations, where cohesiveness is critical. The impact on leaders may be to take accountability of organisational strategy execution failures by stepping down from executive roles. With respect to organisations highly orientated towards future planning, humaneness and achievement, the impact may be for leaders to elevate these aspects in their leadership styles to successfully execute the organisational strategy. In organisations where power is unequally distributed, leaders who impact the organisation positively may be highly respected and in most cases their behaviour may be imitated by others in the organisation.

\section{Rewards}

There is a statistically significant correlation between seven of the nine organisational culture dimensions and the strategy execution dimension of reward. In the sample, a cultural orientation of achievement and power distance were the most conducive to reward systems in the organisation. From a successful strategy execution perspective, reward systems are an important part of strategy execution since they motivate employees to contribute their best. The effectiveness of a reward system can be judged by the willingness of employees to move beyond their day-to-day jobs and voluntarily exert effort to implement strategic initiatives to the best of their abilities. The Cameron \& Quinn (2006) competing values, as well as the Denison \& Mishra (1995) organisational culture frameworks, highlight that rewarding employees for the right behaviour or display of values is an important part of building organisational culture. For example, an organisation that places high emphasis on the value of customer management may reward employees that exhibit excellent service to external customers.

In-group collectivism which promotes cohesiveness seeks to reward teamwork as opposed to individual goals. Achievement orientation, which promotes excelling at meeting goals, is conducive to emphasising rewards. There is an association between the organisational culture dimension of power distance and the strategy execution dimension of rewards. Where power is unequally shared in power distance cultures, it offers upper management greater power to allocate rewards. 


\section{Performance}

A statistically significant correlation exists between seven of the nine organisational culture dimensions and the strategy execution dimension of performance. The literature posits that successful strategy execution requires a performance process; a focus on setting goals and measuring those critical success factors that assure goal attainment and strategy execution. These performance goals need to stretch people, reflecting the ever-changing competitive landscape in which organisations are expected to operate (Schneider et al. 1991).

This research confirms a significant association between organisational culture and the strategy execution dimension of performance. Assertiveness concerns the degree of confrontation among employees in the organisation. Performance in strategy execution requires accountability and holding team members to task. This can often equate to having confrontational conversations which are open and honest within teams. While there is a significant relationship, it is a medium strong association. In highly collectivistic organisations, cohesiveness among team members can be a make or break factor for excellent performance in strategy execution. With respect to organisations highly orientated towards future planning and humaneness, investing for the future and demonstrating fairness within teams are key success factors for good performance in strategy execution. In organisations with a high power distance, there is even more emphasis on performance.

\section{Structure}

For the sample group, there is a statistically significant correlation between eight of the nine organisational culture dimensions and the strategy execution dimension of structure. The Cameron and Quinn (2006) competing values framework states that culture types, i.e. clan, adhocracy, hierarchy and market, require that the organisation be structured in a manner that allows the dimensions of the culture type to be fostered. For example, an organisation with a hierarchy culture type will have a certain degree of power distance. As a result, its structure will have a fair amount of management levels, controls and procedures in place that govern how people work and what they do. The literature posits that successful strategy implementation requires effective organisational structures. Structural variables include the actual design of the organisation, management levels, controls and procedures, etc. These variables combined provide a framework in which companies operate effectively. To successfully execute on strategy, some type of formal structure is needed within the organisation which allows it to operate effectively. Structural variables offer an execution toolkit for highlighting key levers that could affect the formulation-implementation process. Strategies are cascaded and implemented through the organisational structure (Bonoma \& Crittenden, 1988).

This research confirms a significant association between organisational culture and the strategy execution dimension of structure. Uncertainty avoidance refers to the extent to which members of an organisation rely on structures, social norms, rituals and bureaucratic practices to avoid uncertainty and unpredictability of future events. Within this organisational structure for strategy execution there will be rules, norms and practices. In highly collectivistic organisations, a structure that promotes cohesiveness among team members can be a deciding factor for excellent performance in strategy execution. With respect to organisations highly orientated towards achievement, having a structure that allows the company to achieve its goals is the key ingredient for successful strategy execution. In organisations with a high degree of power distance, it can be expected that there would a large focus on structure to enable the different levels of power to work together towards delivering the goal of strategy execution.

\section{Employee Commitment}

There is a statistically significant correlation between all nine organisational culture dimensions and the strategy execution dimension of employee commitment 1. However, only five of the nine associations are medium relationships and there are no strong relationships. A statistically significant correlation exists between seven the nine organisational culture dimensions and the strategy execution dimension of employee commitment 2, but none of these are strong relationships. However, for both these dimensions of strategy execution, namely employee commitment 1 and 2 , achievement orientation has the strongest association.

Successful strategy execution requires employee commitment, regardless of management level. Employee commitment reflects the degree to which employees are determined to see the strategy effectively implemented, 
ultimately becoming part of the organisation. In most organisations, the emphasis with respect to employee commitment has been placed on gaining commitment to how things are done; little emphasis has been placed on gaining commitment to what is done (Parnell, Carraher \& Holt, 2002).

Over time, employees respond to the organisational culture and alter their behaviours and styles. This is particularly evident in the Project Globe cultural dimensions of in-group collectivism, which refer to the degree to which members of an organisation express pride, loyalty, cohesiveness and commitment in their organisations. In other words, the culture of the organisation closely affects the way people behave and thus their commitment to the organisation which they express in the form of pride, loyalty and the way they do things. Organisations highly orientated towards future planning and achievement would prompt commitment by employees to execute the project pipeline successfully and thus influence them to commit to achieving specific goals to ensure future growth of the organisation.

\section{Coordination}

Seven of the nine organisational culture dimensions had significant relationships with the strategy execution dimension of coordination. Successful strategy implementation requires adequate coordination within the organisation. Coordination refers to the participation and collaboration between members within the organisation's labour force, whether the implementation involves the expansion of a product line, new product development, or the merger and acquisition of a new company to enable the organisation to remain relevant in the marketplace (Crittenden \& Crittenden, 2008). Achieving good coordination can be a complex matter for many organisations but is important for execution success (Hrebiniak, 2005a).

In-group collectivism concerns the degree to which individuals express pride, loyalty and cohesiveness in their organisations. To operate as a cohesive unit there needs to be a high level of coordination between employees, leaders and teams. With respect to organisations orientated towards future planning and achievement, to successfully plan for and invest in the future and ensure goal attainment, there must be a high degree of coordination. This will allow teams to work closely together to appropriately realise their synergies as a competitive advantage for future planning.

Future orientation would have the strongest influence on coordination, next to achievement orientation. Coordination is the only strategy execution dimension that is not most influenced by achievement orientation. The humane orientated organisational culture fosters an environment where employees are concerned with each other's well-being and thus influences their coordination amongst each other. In addition to this, to successfully achieve goals, teams need to be able to coordinate the use of resources to maximise output and efficiency. Power distance does not have a significant influence on coordination and thus cannot assist with coordination, perhaps since the influence of power distance is stronger with regards to rewards, structure and leadership. In power distance environments, it can be challenging to achieve high levels of co-ordination as employees with a lower power base may feel disempowered and be reluctant to coordinate as a result.

\section{Overall Model}

The canonical correlation analysis, using the nine dimensions of culture dimensions as predictors of the eight strategy execution variables, reveals that the full model across all functions is statistically significant using the Wilk's criterion. The regression equations for each dependent variable separately show that achievement orientation is statistically significant across all dimensions of strategy execution and thus has the greatest impact. This finding has not been explicitly discussed in the literature and has been relatively unexamined. Overall there has been limited research into the effects of organisational culture dimensions on strategy execution dimensions. This finding therefore adds to the body of knowledge on the relationships between the constructs of organisational culture and strategy execution, as well as the relationships between the dimensions of the organisational culture and strategy execution.

In addition to the canonical analysis, the researcher also conducted a control variable analysis which showed that management level has an influence on the organisational culture dimensions and the strategy execution of leadership. In addition, the organisation strategy (i.e. growth, low cost, innovation, etc.) influences the relationship between culture dimensions and the strategy execution dimension of employee commitment. 


\section{CONCLUSION}

The effects of organisational culture on performance, ranging from employee satisfaction, financial performance and market performance to innovation, have all been investigated. The impact of organisational culture on other variations of strategy execution, however, remains relatively unexplored. There is also limited research into the impact of organisational culture dimensions on strategy execution dimensions. This study adds to the body of knowledge on the relationship between the constructs of organisational culture and strategy execution. Overall, the results support the findings of studies which have investigated the effect of organisational culture on performance. It has shown that the dimensions of organisational culture have a variation of strong, medium and weak associations with the dimensions of strategy execution.

House et al. (2001) found that the culture of the organisation closely affects the way people behave and thus their commitment to the organisation, which they express in the form of pride, loyalty and the way they do things. From a practical perspective, it can be concluded from these findings that an increased focus on organisational culture dimensions will have an increased impact on employee commitment to successfully execute on the organisation's strategy. The questionnaire items under employee commitment relate to employees' personal accountability and commitment to executing strategies for the organisation, irrespective of their department, job and team. The sample group for this study is at management level and is thus expected to deal with cross-functional execution and not be bound to department, team and job.

\section{Limitations of the Research and Recommendations for Future Studies}

The sample was restricted to one FMCG company and therefore the findings are limited and cannot be generalised to all companies. The research is a cross-sectional study, which does not provide the depth of analysis of a longitudinal study. It was limited to focus on organisational culture dimensions and only investigated the relationships between organisational culture and strategy execution; it did not examine other factors that influence strategy execution, such as strategy formulation. The most significant bias was that of non-response bias, primarily refusal to respond to the questionnaire (Saunders et al. 2009), which could have skewed the results, or self-selection bias, whereby those who chose to respond are those who felt strongly about the subject, thereby skewing the result (Saunders \& Lewis, 2012).

The current study collected data from 281 employees from the same FMCG company, where all respondents were in management level and therefore very similar, resulting in less variety of responses. The researchers recommend widening the scope of this study, to empirically investigate if the results are consistent when sampling respondents from different types of companies, and with more variety in employee roles and jobs. Future research could conduct a study across multiple organisations, sectors and countries to develop more generally applicable conclusions. A future study could investigate the organisational culture types detrimental to strategy execution. This study's finding of the organisational culture dimensions like achievement orientation need to be addressed by organisations and is discussed in the next section.

\section{Implications for Organisations}

The literature on organisational culture and strategy execution reveals that organisations that cultivate culture, and operationalise it effectively, stand to benefit the most in terms of employee productivity towards executing the organisational strategy. It is important that employees embrace the organisational culture and absorb the shared values. In addition, top management should provide precise guidelines and direction for performance to encourage and gain commitment from employees to achieve the company's objectives.

The cultural dimensions that organisations deem to be valuable will impact the way leaders conduct themselves to achieve successful strategy execution. It is important for management to understand that cultural aspects play an important role in defining leadership behaviours. Weaving the dimension of achievement into an organisation's values and practices will play a huge role in defining its performance in strategy execution. Leadership must foster and develop an organisational culture that rewards employees for successful strategy execution, as it is this aspect that keeps employees motivated to create processes for strategy execution and remain committed. The leaders in the organisation must be role models of achievement orientation and showing their support of goal directed employees. 
Achievement orientation and future focus should be criteria in the selection process of applicants.

The organisational cultural dimensions that management believes hold value will impact the way teams work to successfully execute the organisation's strategy. The type of culture dimensions that an organisation wants to institute will largely affect the type of structure it puts in place. The structure has a major impact on the ability to execute the strategy successfully, since there are several aspects within a structure that create a framework for the organisation to operate effectively. Leaders of organisations need to be cognisant that the organisational culture influences the commitment of employees, which is needed for successful strategy execution.

\section{AUTHOR BIOGRAPHIES}

Melissa Reddy was a Gordon Institute of Business Science, University of Pretoria, MBA Alumnus in Johannesburg, South Africa in 2016.

Caren Brenda Scheepers was the supervisor of Melissa Reddy's MBA research in 2016 and authored the article. She is an Associate Professor at the Gordon Institute of Business Science, University of Pretoria, Johannesburg, South Africa.

\section{REFERENCES}

Ahmadi, S. A. A., Alamzadeh, Y., Daraei, M., \& Akbari, J. (2012). Relationship between Organizational Culture and Strategy Implementation: Typologies and Dimensions. Global Business \& Management Research: An International Journal, 4(3/4), 286-299.

Beer, M., \& Eisenstat, R. A. (2000). The Silent Killers of Strategy Implementation and Learning. Sloan Management Review. Retrieved from http://search.ebscohost.com/login.aspx?direct=true\&db=buh\&AN=3358393\&site=ehost-live

Bonoma, T. V., \& Crittenden, V. L. (1988). Managing marketing implementation. Sloan Management Review, $29(2), 7$.

Bossidy, L., Charan, R., \& Burck, C. (2011). Execution: The discipline of getting things done. Random House.

Bruin, J. (2016). SPSS Data Analysis Examples Canonical Correlation Analysis. Retrieved January 13, 2017, from http://www.ats.ucla.edu/stat/spss/dae/canonical.htm

Bujang, M. A., \& Baharum, N. (2016). Sample Size Guideline for Correlation Analysis. World Journal of Social Science Research, 31(1), 37.

Cameron, K. S., \& Quinn, R. E. (2006). Diagnosing and Changing Organizational Culture. The Jossey-Bass Business \& Management Series. http://doi.org/10.1111/j.1744-6570.2006.00052_5.x

Chatman, J. A., \& Cha, S. E. (2003). Leading by leveraging culture. California Management Review, 45(4), 20-34. Retrieved from http://faculty.haas.berkeley.edu/lyons/chatmanleveragingculture.pdf

Chen, C. C., Hen, X.-P., \& Meindl, J. R. (1998). How can cooperation be fostered?. Academy of Management Review, 23(2), 285-304.

Chetty, P., \& Datt, S. (2015). Interpretation of factor analysis using SPSS. Retrieved January 10, 2017, from https://www.projectguru.in/publications/interpretation-of-factor-analysis-using-spss/

Cheung, S. O., Wong, P. S. P., \& Lam, A. L. (2012). An investigation of the relationship between organizational culture and the performance of construction organizations. Journal of Business Economics and Management, 13(4), 688-704. http://doi.org/10.3846/16111699.2011.620157

Cheung, S. O., Wong, P. S. P., \& Wu, A. W. Y. (2011). Towards an organizational culture framework in construction. International Journal of Project Management, 29(1), 33-44. http://doi.org/10.1016/j.ijproman.2010.01.014

Crittenden, V. L., \& Crittenden, W. F. (2008). Building a capable organization: The eight levers of strategy implementation. Business Horizons, 51(4), 301-309. http://doi.org/10.1016/j.bushor.2008.02.003

Denison, D. R., \& Mishra, A. K. (1995). Toward a Theory of Organizational Culture and Effectiveness. Organization Science, $6(2), 204-223$.

Exner, J. E. Ed. (2013). Issues and Methods in Rorschach Research Lea Series in Personality and Clinical Psychology. New York: Routledge.

Gregory, B. T., Harris, S. G., Armenakis, A. A., \& Shook, C. L. (2009). Organizational culture and effectiveness: A study of values, attitudes, and organizational outcomes. Journal of Business Research, 62(7), 673-679.

http://doi.org/10.1016/j.jbusres.2008.05.021

Hair, J., Black, W., Babin, B., Anderson, R., \& Tatham, R. (2006). Multivariate data analysis (6th ed.). Uppersaddle River: Pearson Prentice Hall. 
Heesen, B. (2015). Effective Strategy Execution: Improving Performance with Business Intelligence Management for Professionals (2nd ed.). Springer.

Hofstede, G. (1984). Culture's Consequences: International Differences in Work-Related Values (abridged). SAGE.

Hogan, S. J., \& Coote, L. V. (2014). Organizational culture, innovation, and performance: A test of Schein's model. Journal of Business Research, 67(8), 1609-1621. http://doi.org/10.1016/j.jbusres.2013.09.007

Hoppe, M. H., \& Eckert, R. (2015). Leader Effectiveness and Culture: The GLOBE Study. Centre for Creative Leadership, 1, 117. https://gdl29.files.wordpress.com/2014/03/globestudy.pdf

House, R. J., Hanges, P. J., Javidan, M., Dorfman, P. W., \& Gupta, V. (2004). Culture, Leadership, and Organizations: The GLOBE Study of 62 Societies. Thousand Oaks, CA: Sage Publications.

House, R. J., Javidan, M., \& Dorfman, P. (2001). Project GLOBE: An Introduction. Applied Psychology 50(4), 489-505. http://doi.org/10.1111/1464-0597.00070

House, R. J., Javidan, M., Hanges, P., \& Dorfman, P. (2002). Understanding cultures and implicit leadership theories across the globe: An introduction to project GLOBE. Journal of World Business. 37(1), 3-10. http://doi.org/10.1016/S10909516(01)00069-4

Hrebiniak, L. G. (2005a). Making Strategy Work: Leading Effective Execution and Change. Pearson Education.

Hrebiniak, L. G. (2005b). A Strategic Look At Strategy Execution. Optimize, 4(3), 57.

Hrebiniak, L. G. (2006). Obstacles to effective strategy implementation. Organizational Dynamics, 35(1), 12-31. http://doi.org/10.1016/j.orgdyn.2005.12.001

Kaplan, R. S. (2005). How the balanced scorecard complements the McKinsey 7-S model. Strategy \& Leadership, 33(3), 41-46. http://doi.org/10.1108/10878570510594442

Kaplan, R. S. (2012). The balanced scorecard: comments on balanced scorecard commentaries. Journal of Accounting \& Organizational Change, 8(4), 539-545. http://doi.org/10.1108/18325911211273527

Kargas, A. D., Varoutas, D., \& Nisar, T. (2015). On the relation between organizational culture and leadership: An empirical analysis. Cogent Business \& Management, 2(1), 1-18. http://doi.org/10.1080/23311975.2015.1055953

Klein, A. (2011). Corporate culture: its value as a resource for competitive advantage', Journal of Business Strategy, 32(2), 2128. http://doi.org/10.1108/02756661111109743

Krishnakumar, M. (2015). Strategy Implementation : Strategic Change Model - A Conceptual Frame Work. Strategic Management Review, 9(1), 77-86.

Li, D-y \& Liu, J. (2014). Dynamic capabilities, environmental dynamism, and competitive advantage: Evidence from China. Journal of Business Research, 67(1), 2793-2799. http://doi.org/10.1016/j.jbusres.2012.08.007

Linnenluecke, M. K., \& Griffiths, A. (2010). Corporate sustainability and organizational culture. Journal of World Business, 45(4), 357-366. http://doi.org/10.1016/j.jwb.2009.08.006

MacCormack, A., Dunn, B., \& Kemerer, C. F. (2012). Research In Motion: The mobile OS platform war. Harvard Business Review, Case study 613001, 1-22.

MacLennan, A. (2010). Strategy Execution: Translating Strategy Into Action in Complex Organizations. New York: Taylor and Francis.

Miller, D., Eisenstat, R., \& Foote, N. (2002). Strategy from the Inside Out: Building capability-creating organizations. California Management Review, 44(3), 37-54. http://doi.org/10.2307/41166131

Minkov, M., \& Blagoev, V. (2012). What do Project GLOBE's cultural dimensions reflect? An empirical perspective. Asia Pacific Business Review, 18(1), 27-43. http://doi.org/10.1080/13602381.2010.496292

Minkov, M., \& Hofstede, G. (2011). The evolution of Hofstede's doctrine. Cross Cultural Management: An International Journal, 18(1), 10-20. http://doi.org/10.1108/13527601111104269

Mumford, M. D., Scott, G. M., Baddis, B., \& Strange, J. M. (2002). Leading creative people: Orchestrating expertise and relationships. Leadership Quarterly, 13, 705-750. http://doi.org/10.1016/S1048-9843(02)00158-3

Nayak, B., \& Barik, A. (2013). Assessment of the Link Between Organizational Culture and Job Satisfaction (Study of an Indian Public Sector). International Journal of Advanced System and Social Engineering Research, ISSN 3, 2278-6031. Retrieved from http://www.bipublication.com

Nielson, G. L., Martin, K. L., \& Powers, E. (2008). The secrets to successful strategy execution. Harvard Business Review, June, 83-93.).

O’Reilly, C. A., Caldwell, D. F., Chatman, J. A., Lapiz, M., \& Self, W. (2010). How leadership matters: The effects of leaders' alignment on strategy implementation. Leadership Quarterly, 21(1), 104-113. http://doi.org/10.1016/j.leaqua.2009.10.008

Okumus, F. (2006). Towards a strategy implementation framework. International Journal of Contemporary Hospitality Management, 13(7), 327-338.

Olson, E. M., Slater, S. F., \& Hult, G. T. M. (2005). The importance of structure and process to strategy implementation. Business Horizons, 48(1), 47-54. http://doi.org/10.1016/j.bushor.2004.10.002

Pallant, J. (2010). SPSS Survival Manual: A Step by Step Guide to Data Analysis using SPSS for Windows. Open University Press (4th ed.). London.

Pandey, K. N. (2016). Paradigms of Knowledge Paradigms of Knowledge Management: With Systems Modelling Case Studies Volume 60 of Studies in Systems, Decision and Control. Springer India, 2016. 
Parnell, J. A., Carraher, S., \& Holt, K. (2002). Participative Management's influence on effective strategic diffusion. Journal of Business Strategies, 19(2), 161-186.

Parnell, J. A. (2008). Strategy execution in emerging economies: assessing strategic diffusion in Mexico and Peru. Management Decision, 46(9), 1277-1298. http://doi.org/10.1108/00251740810911948

Patten, L. (2015). The Continued Struggle with Strategy Execution. International Journal of Business Management and Economic Research, 6(5), 288-295.

Prajogo, D. I., \& McDermott, C. M. (2011). The relationship between multidimensional organizational culture and performance. International Journal of Operations \& Production Management, 31(7), 712-735. http://doi.org/10.1108/01443571111144823

Pryor, M. G., Anderson, D., Toombs, L. A., \& Humphreys, J. H. (2007). Strategic Implementation as a Core Competency The 5P ' s Model. Journal of Management Research, 7(1), 3-17.

Radomska, J. (2014). Model of Successful Strategy Execution : Revising the Concept. Problems of Management in the 21st Century, 9(3), 213-222.

Rajasekar, J., \& Khoud, A. (2014). Factors affecting Effective Strategy Implementation in a Service Industry: A Study of Electricity Distribution Companies in the Sultanate of Oman. International Journal of Business and Social Science, 5(9), 169-183. Retrieved from http://mustangjournals.com/MJMM/v3_MJMM_2013.pdf\#page=120

Reddy, M. (2016). The effect of organisational culture on strategy execution. (Unpublished research study towards MBA degree), Gordon Institute of Business Science, University of Pretoria. Pretoria: University repository.

Rothgeb, J. R. (2008). Encyclopedia of Survey Research Methods. Thousand Oaks: Sage Publications, Inc.

Saunders, M., \& Lewis, P. (2012). Doing Research in Business and Management: An Essential Guide to Planning Your Project. Essex: Pearson Education Limited.

Saunders, M., Lewis, P., \& Thornhill, A. (2009). Research Methods for Business Students. Essex: Pearson Education Limited.

Schaap, J. I. (2012). Strategy Implementations - Can Organizations Attain Outstanding Performance? Strategic Management Review, 6(1), 98-121. http://doi.org/10.4128/1930-4560-6.1.98

Schein, E. H. (1992). Organizational culture and leadership. San Francisco: Jossey-Bass Inc. Scott.

Schneider, B., Ehrhart, M. G., \& Macey, W. H. (2013). Organizational climate and culture. Annual Review of Psychology, 64, 361-388. http://doi.org/10.1146/annurev-psych-113011-143809

Schneier, C. E., Shaw, D. G., \& Beatty, R. W. (1991). Performance Measurement and Management : A Tool for Strategy Execution. Human Resource Management, 30(3), 279-301.

Sekaran, U. (2005). Research Methods for Business: A Skill-building Approach (4th ed.). New York: John Wiley \& Sons.

Shah, A. M. (2005). The Foundations of Successful Strategy Implementation: Overcoming the Obstacles. Global Business Review 6(2005), 293-302. http://doi.org/10.1177/097215090500600208

Sharifirad, M. S., \& Ataei, V. (2012). Organizational culture and innovation culture: exploring the relationships between constructs. Leadership \& Organization Development Journal, 33(5), 494-517. http://doi.org/10.1108/01437731211241274

Wu, M. (2006). Hofstede's Cultural Dimensions 30 Years Later : A Study of Taiwan and the United States. Intercultural Communication Studies, $X V(1), 33-42$.

Yesil, S., \& Kaya, A. (2013). The Effect of Organizational Culture on Firm Financial Performance: Evidence from a Developing Country. Procedia - Social and Behavioral Sciences, 81, 428-437. http://doi.org/10.1016/j.sbspro.2013.06.455

Zheng, W., Yang, B., \& McLean, G. N. (2010). Linking organizational culture, structure, strategy, and organizational effectiveness: Mediating role of knowledge management. Journal of Business Research, 63(7), 763-771. http://doi.org/10.1016/j.jbusres.2009.06.005 


\section{APPENDIX}

Summary table of literature on strategy execution dimensions

\begin{tabular}{|c|c|}
\hline \multicolumn{2}{|c|}{ Key Dimensions of Strategy Execution } \\
\hline Coordination & $\begin{array}{l}\text { - Participation and collaboration between members of the organisation's labour force (Crittenden \& } \\
\text { Crittenden, 2008) } \\
\text { - Achieving good coordination can be a complex matter for many organisations but is important for } \\
\text { execution success (Hrebiniak, 2005a; Schaap, 2012; Beer \& Eisenstat, 2000). }\end{array}$ \\
\hline Information sharing & $\begin{array}{l}\text { - The deployment of critical information is usually made easier when there is no confusion of roles and } \\
\text { responsibilities between members within the organisation (Hrebiniak, 2006; Patten, 2015) }\end{array}$ \\
\hline Competence & $\begin{array}{l}\text { - The development of world class capabilities or competencies that lead to organisations developing a } \\
\text { sustainable competitive advantage and could be applied across numerous business functions (Pryor } \\
\text { et al. 2007). } \\
\text { - Core competency refers to what an organisation does best along the dimensions of people, } \\
\text { management practices, processes, systems, technology, and customer relationships (Kaplan, 2005; } \\
\text { Radomska, 2014) }\end{array}$ \\
\hline $\begin{array}{l}\text { Employee's } \\
\text { Commitment }\end{array}$ & $\begin{array}{l}\text { - Employee commitment refers to the degree to which employees are determined to see the strategy } \\
\text { successfully executed, ultimately becoming part of the organisation (Parnell, 2008; Okumus, 2006). } \\
\text { - Should include commitment to "how things are done" and commitment to "what is done" (Parnell, } \\
\text { 2008; Okumus, 2006). }\end{array}$ \\
\hline Leadership & $\begin{array}{l}\text { - Effective leadership is required to implement strategic initiatives, reinforce the strategy with lower } \\
\text { employee levels, allocate resources to the strategic initiatives, deal effectively with resistance to the } \\
\text { strategic changes and influence the mind-set of employees to buy into the strategic change (O'Reilly } \\
\text { et al. 2010; Rajasekar \& Khoud, 2014). }\end{array}$ \\
\hline Change & $\begin{array}{l}\text { - Strategy execution is a continuous, dynamic, never-ending, integrated and interactive process } \\
\text { requiring continuous reassessment and reformulation. Therefore it requires change strategies which } \\
\text { are robust in gaining the confidence and support of employees which is needed to make the change a } \\
\text { reality (Krishnakumar, 2015). }\end{array}$ \\
\hline Structure & $\begin{array}{l}\text { - Structural variables of an organisation include the actual design of the organisation, the management } \\
\text { levels, controls and procedures, etc. These variables combined provide a framework in which } \\
\text { companies operate effectively (Olson et al. 2005; Bonoma \& Crittenden, 1988). } \\
\text { - Structural variables offer an execution toolkit for highlighting key levers that could affect the } \\
\text { formulation-implementation process. Strategies are cascaded and implemented through the } \\
\text { organisational structure (Olson et al. 2005; Bonoma \& Crittenden, 1988). }\end{array}$ \\
\hline $\begin{array}{l}\text { A good rewards } \\
\text { system }\end{array}$ & $\begin{array}{l}\text { - Reward systems play an important role in developing "commitment, loyalty and interest" in } \\
\text { employees. (Shah, 2005; Schaap, 2012). }\end{array}$ \\
\hline Performance & $\begin{array}{l}\text { - Successful strategy implementation requires a performance process. A focus of setting goals and } \\
\text { measuring those critical success factors that assures goal attainment and strategy execution. These } \\
\text { performance goals need to stretch people, reflecting the ever changing competitive landscape that } \\
\text { organisations are expected to operate in (Schneier et al. 1991). }\end{array}$ \\
\hline
\end{tabular}


NOTES 